
\title{
25 Research Soure \\ Influence of the Spatial Distribution Pattern of Buildings on the Distribution of PM2.5 Concentration
}

\section{Zhixuan Zhang}

Shandong Jianzhu University

Baoyan Shan ( $\sim$ shan7066@sdjzu.edu.cn )

Shandong Jianzhu University https://orcid.org/0000-0003-2364-2906

Qikai Lin

Shandong Jianzhu University

Yanqiu Chen

Shandong Jianzhu University

Xinwei Yu

Shandong Jianzhu University

\section{Research Article}

Keywords: spatial distribution pattern of buildings, PM2.5 concentration, correlation analysis, Kriging interpolation, spatial and temporal differences

Posted Date: April 26th, 2021

DOI: https://doi.org/10.21203/rs.3.rs-429008/v1

License: (c) (1) This work is licensed under a Creative Commons Attribution 4.0 International License. Read Full License

Version of Record: A version of this preprint was published at Stochastic Environmental Research and Risk Assessment on October 20th, 2021. See the published version at https://doi.org/10.1007/s00477021-02118-6. 


\section{Abstract}

The spatial distribution pattern of buildings is an entry point for controlling the diffusion of pollution particles at an urban spatial structure scale. In this study, we adopted ordinary kriging interpolation and other methods to study the spatial distribution pattern of PM2.5 and constructed urban spatial structure indexes based on building distribution patterns to reveal the influence of building spatial distribution patterns on PM2.5 concentration across the study area and at different elevations. The present study suggests that: (1) Topographic elevation is an important factor influencing the distribution of PM2.5; the correlation coefficient reaches -0.761 and exceeds the 0.001 confidence level. As the elevation increases, the urban spatial structure indexes show significant correlations with PM2.5, and the regularity becomes stronger. (2) The PM2.5 concentration is negatively correlated with the mean and standard deviation of the DEM, the mean and maximum absolute building height, the outdoor activity area, and the average distance between adjacent buildings; and is positively correlated with the sum of the building base area, the building coverage ratio, the space area, the building coverage ratio, the space occupation ratio, and the sum of the building volume. These urban spatial structure indexes are important factors affecting PM2.5 concentration and distribution and should be considered in urban planning. (3) Spatio-temporal differences in PM2.5 concentration and distribution were found at different elevation and time ranges. Indexes, such as the average building height, the average building base area, the sum of the building volume, and the standard deviation of building volume experienced significant changes. Higher PM2.5 concentration yielded a more significant influence of urban spatial structure indexes on PM2.5 distribution. More discrete spatial distributions of PM2.5 yielded weaker correlations between PM2.5 concentrations and the urban spatial structure indexes.

\section{Full Text}

This preprint is available for download as a PDF.

\section{Figures}




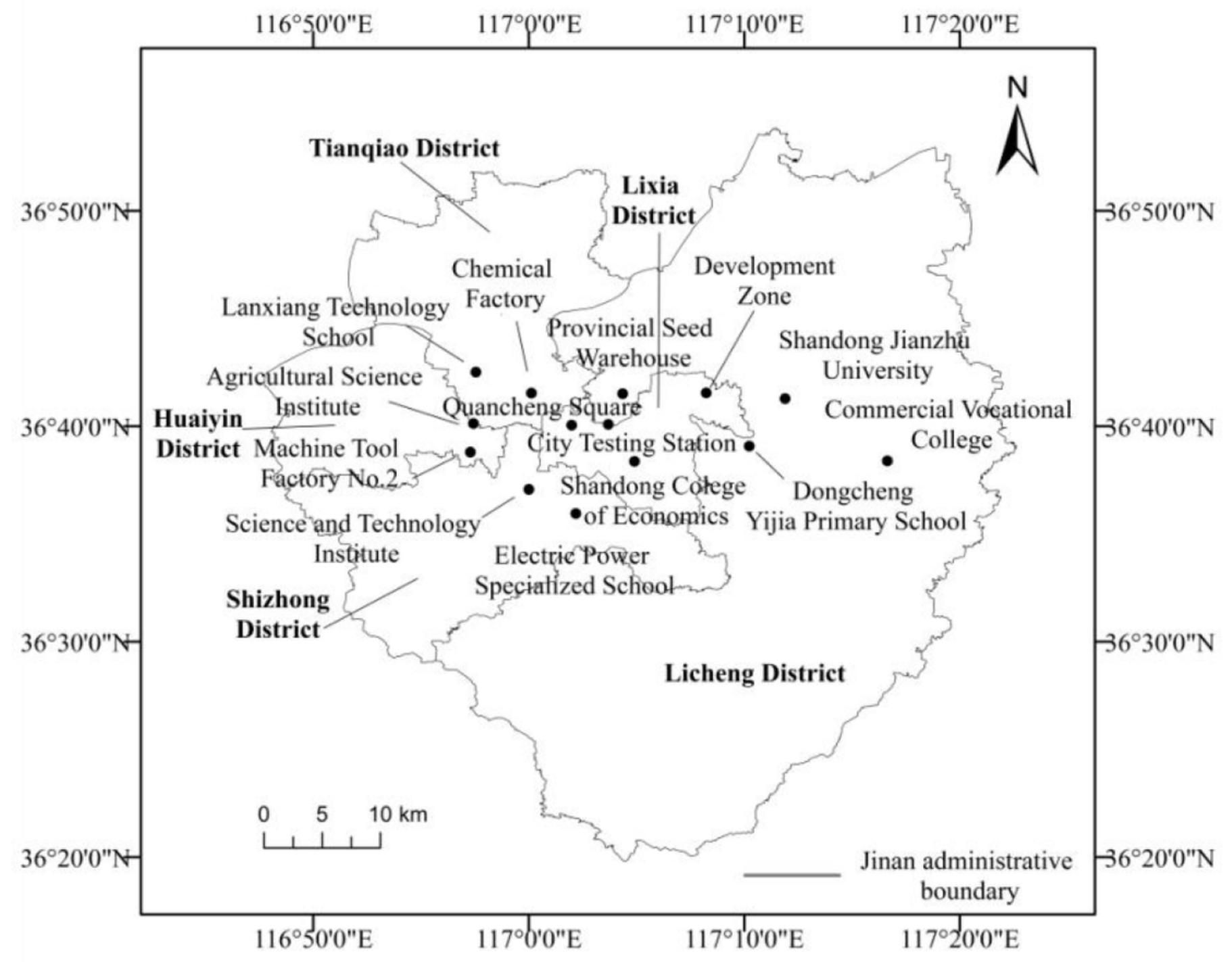

\section{Figure 1}

Distribution of air quality monitoring stations in the study area Note: The designations employed and the presentation of the material on this map do not imply the expression of any opinion whatsoever on the part of Research Square concerning the legal status of any country, territory, city or area or of its authorities, or concerning the delimitation of its frontiers or boundaries. This map has been provided by the authors. 

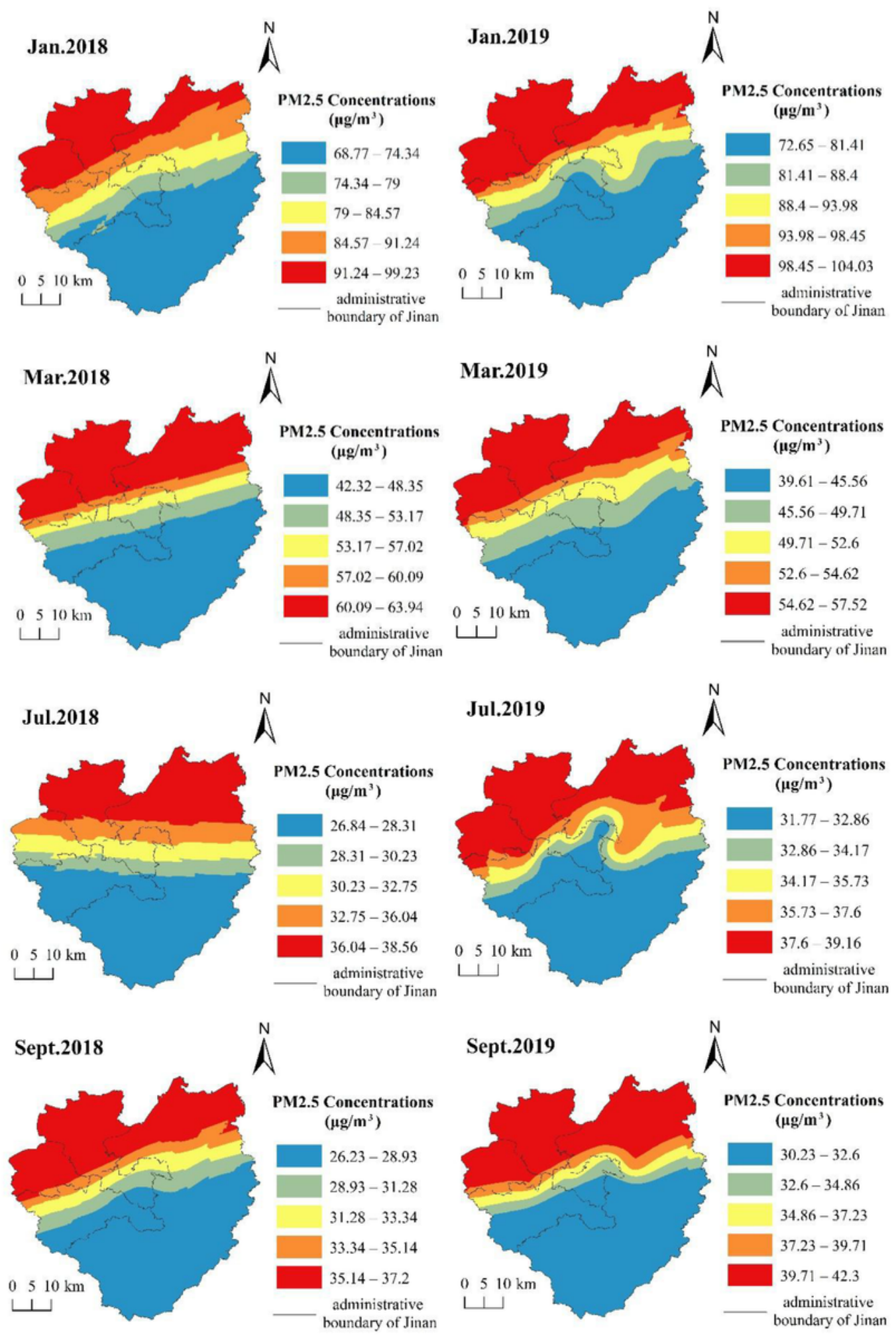

\section{Figure 2}

Interpolation results of PM2.5 concentrations in the study area (partial) Note: The designations employed and the presentation of the material on this map do not imply the expression of any opinion whatsoever on the part of Research Square concerning the legal status of any country, territory, city or area or of its authorities, or concerning the delimitation of its frontiers or boundaries. This map has been provided by the authors. 


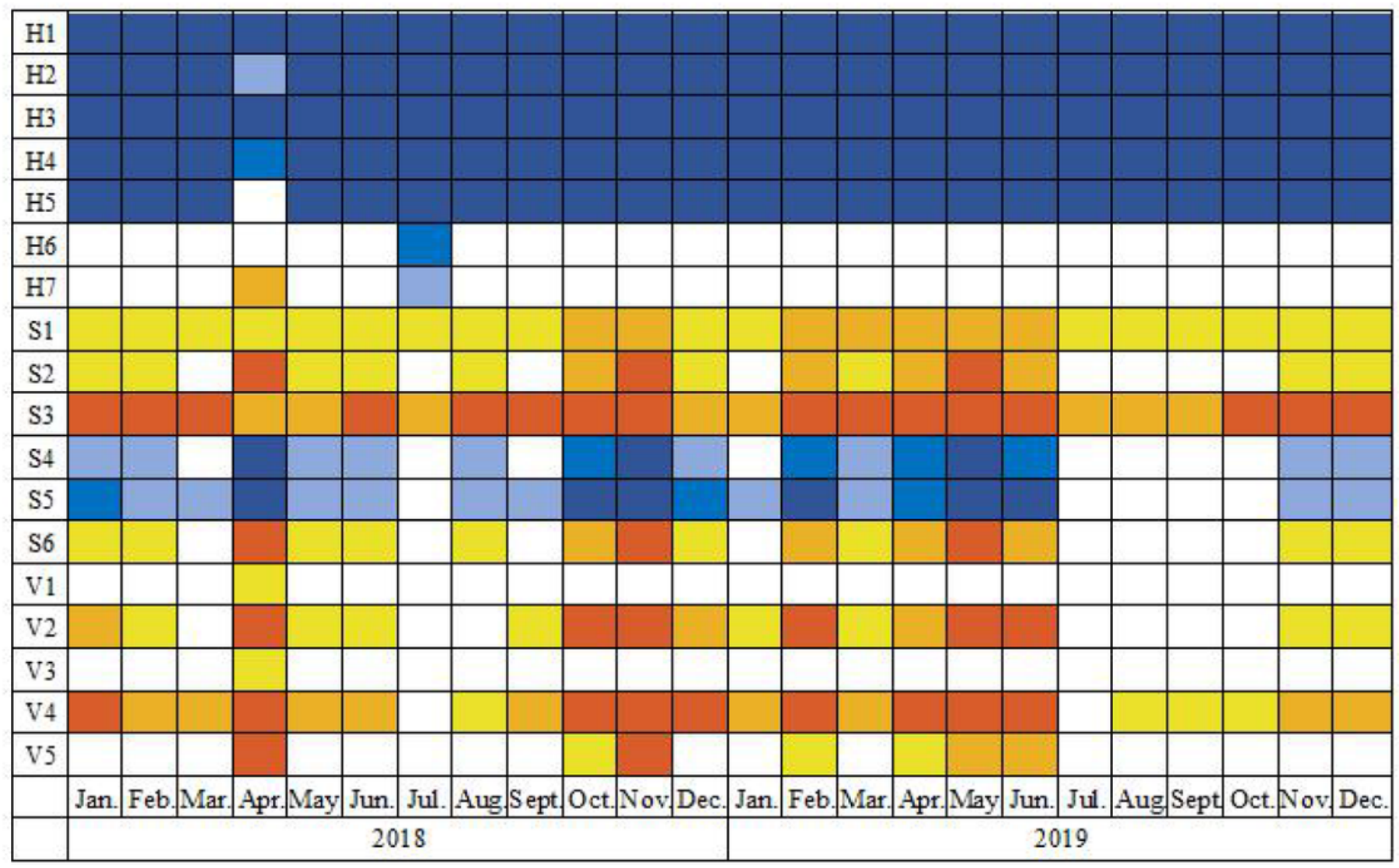

\begin{tabular}{|c|c|c|c|c|}
\hline \multirow{3}{*}{$\begin{array}{l}\text { Positive } \\
\text { Correl ati on }\end{array}$} & 0.001 Significance & \multirow{3}{*}{$\begin{array}{l}\text { Negatively } \\
\text { correl ation }\end{array}$} & 0.001 Significance & \multirow{3}{*}{$\begin{array}{c}\text { Not } \\
\text { Significant }\end{array}$} \\
\hline & 0.01 Significance & & 0.01 Significance & \\
\hline & 0.05 Significance & & 0.05 Significance & \\
\hline
\end{tabular}

\section{Figure 3}

Results of the analysis of PM2.5 concentrations and urban spatial structure indexes from 2018-2019 


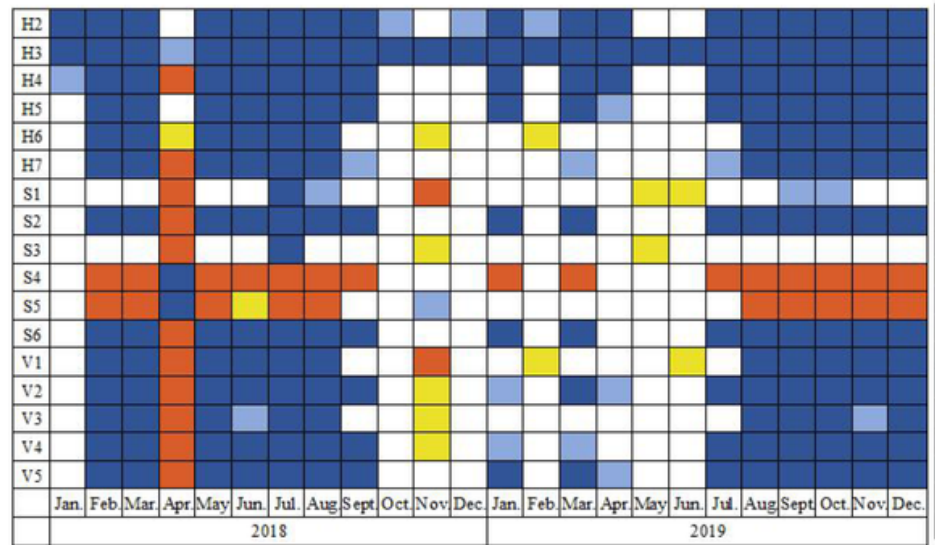

(level 1)

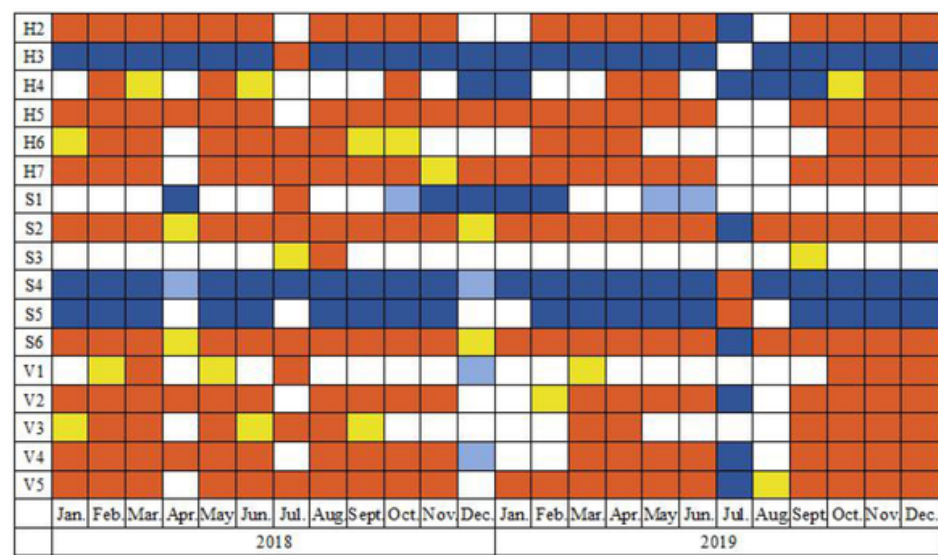

(level 3)

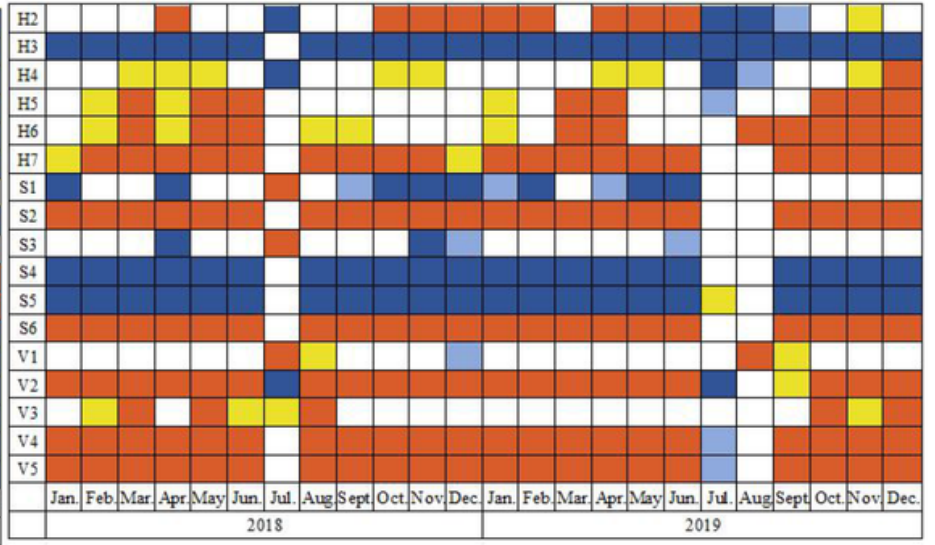

(level 2)

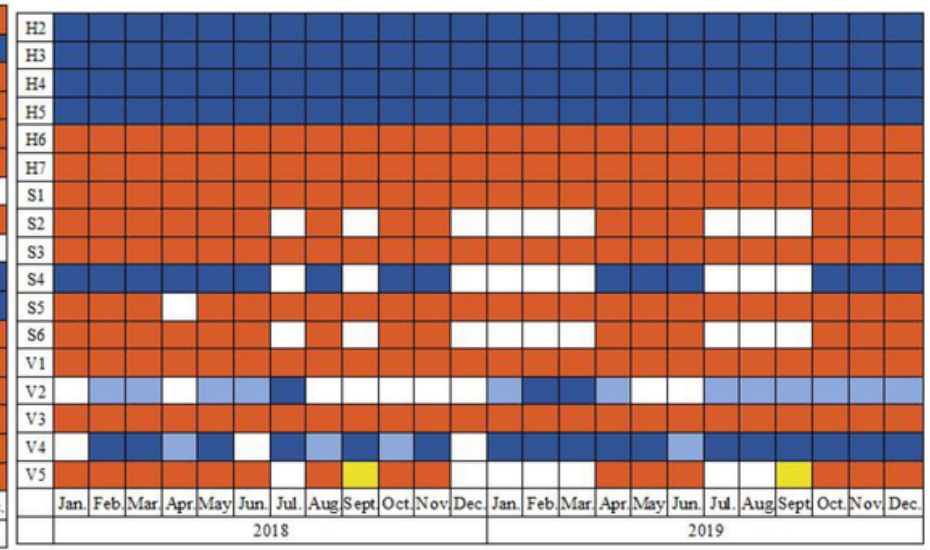

(level 4)

\begin{tabular}{|c|c|c|c|c|}
\hline \multirow{2}{*}{$\begin{array}{c}\text { Positive } \\
\text { Correlation }\end{array}$} & 0.01 Significance & \multirow{2}{*}{$\begin{array}{l}\text { Negatively } \\
\text { correl ation }\end{array}$} & 0.01 Significance & \multirow{2}{*}{$\begin{array}{c}\text { Not } \\
\text { Significant }\end{array}$} \\
\hline & 0.05 Significance & & 0.05 Significance & \\
\hline
\end{tabular}

\section{Figure 4}

Results of correlation analysis between PM2.5 and urban spatial structure indexes graded by elevation 